\title{
Dinâmica do Herbicida Amicarbazone (Dinamic) Aplicado sobre PAlHa de CANA-DE-AÇÚCAR (Saccarum officinarum) ${ }^{1}$
}

\author{
Performance of Amicarbazone Applied on Sugarcane Straw \\ CAVENAGHI, A.L. ${ }^{2}$, ROSSI, C.V.S. ${ }^{3}$, NEGRISOLI E. ${ }^{4}$, COSTA, E.A.D. ${ }^{5}$, VELINI, E.D. ${ }^{6}$ e \\ TOLEDO, R.E.B. ${ }^{7}$
}

\begin{abstract}
RESUMO - O objetivo deste trabalho foi estudar a dinâmica do herbicida amicarbazone (Dinamic) aplicado sobre palha de cana-de-açúcar deixada sobre o solo, em sistema de cana crua. Três ensaios foram realizados para avaliar a dinâmica desse herbicida aplicado sobre diferentes quantidades de palha de cana-de-açúcar, em diferentes intervalos de tempo e volumes de simulação de chuvas após aplicação do herbicida. No primeiro ensaio, foi avaliada a interceptação do herbicida por $0,1,2,5,5,7,5,10,15$ e 20 t de palha de cana-deaçúcar ha ${ }^{-1}$. A lixiviação do herbicida em $5,10,15$ e $20 \mathrm{t}$ de palha ha ${ }^{-1}$ foi avaliada sob simulação de chuva de 2,5, 5, 10,15,20, 35 e $65 \mathrm{~mm}$, um dia após a aplicação (DAPC) do segundo ensaio. As chuvas foram acumulativas, aplicando-se de 2,5 em 2,5 mm. No terceiro ensaio, foi avaliado o efeito dos intervalos de tempo entre a aplicação do herbicida e a primeira chuva na lixiviação do herbicida Dinamic $\left(0,1,7,15\right.$ e 30 dias) em 10 t de palha ha ${ }^{-1}$, em função das mesmas precipitações simuladas no segundo ensaio. Nos segundo e terceiro ensaios foi realizada uma simulação de $20 \mathrm{~mm}$ em intensidade de $115 \mathrm{~mm} \mathrm{~h}^{-1}$ aos 7 e 14 dias após as primeiras chuvas (DAPC). Os resultados obtidos no segundo e terceiro ensaios foram ajustados pelo modelo de Mitscherlich $\left(\mathrm{Y}=\mathrm{a}^{*}\left(1-10^{-\mathrm{c}^{*}(\mathrm{~b}+\mathrm{x})}\right)\right)$. A quantificação do herbicida foi realizada por cromatografia líquida de alta eficiência. Quantidades de palha iguais ou superiores a $5 \mathrm{t} \mathrm{ha}^{-1}$ apresentam interceptação quase que total do herbicida no momento da aplicação, sendo nula a transposição. Com o aumento da quantidade de palha, ocorreu diminuição na quantidade de herbicida lixiviado pela ação da chuva simulada, principalmente para valores de 15 e $20 \mathrm{t}$ de palha de cana-de-açúcar ha ${ }^{-1}$. Quanto maior o intervalo de tempo entre a aplicação do herbicida e a primeira chuva, menor é a lixiviação total do produto. Em relação às chuvas aos 7 e 14 DAPC, no segundo e terceiro ensaios, foram observadas pequenas quantidades extraídas do herbicida, considerando-se que grande parte do amicarbazone foi lixiviada com as primeiras chuvas, que indicaram que os primeiros $20 \mathrm{~mm}$ de chuva simulada foram importantes para lixiviação da maior parte do amicarbazone (Dinamic) retido pela palha no momento da aplicação.
\end{abstract}

Palavras-chave: amicarbazone, herbicidas, palhada, lixiviação.

ABSTRACT - In order to better understand the dynamics of the herbicide amicarbazone (Dinamic) applied on sugarcane straw left on the soil under the crude cane system, three assays were carried out to evaluate the performance of this herbicide applied on different amounts of sugarcane straw in different periods and under different rainfall intensities after its application. In the first assay, herbicide interception was assessed by $0,1,2.5,5,7.5,10,15$ and $20 t h^{-1}$ of straw. In the second assay, herbicide leaching through 5, 10, 15 and $20 \mathrm{th} \mathrm{ha}^{-1}$ of straw was evaluated

1 Recebido para publicação em 19.4.2007 e na forma revisada em 29.11.2007.

2 Prof., Dr., UNIVAG - Centro Universitário, Av. Dom Orlando Chaves, 2.655 - Cristo Rei, 78118-000. Várzea Grande, MT. <alcavenaghi@uol.com.br>; ${ }^{3}$ Eng $^{\mathrm{a}}$-Agr ${ }^{\mathrm{a}}$, M.Sc., Doutorando em Agricultura. FCA/Unesp - Botucatu, SP. Fazenda Experimental Lageado, Caixa Postal 237, 18603-970, Botucatu, SP, <cavsr@fca.unesp.br>; ${ }^{4}$ Eng-Agr ${ }^{\circ}$,. Dr., FCA/Unesp - Botucatu, SP. Fazenda Experimental Lageado, Caixa Postal 237, 18603-970, Botucatu, SP, <ednegri@fca.unesp.br>; ${ }^{5}$ Pesq., Dr., Unidade de Pesquisa e Desenvolvimento de Ubatuba, APTA. Rod. Oswaldo Cruz, 5061, 13680-000, Ubatuba, SP. ${ }^{6}$ Prof., Dr., Dep. de Agricultura FCA/Unesp - Botucatu, SP, Fazenda Experimental Lageado, Caixa Postal 237, 18603-970, Botucatu, SP, $<$ velini@fca.unesp.br>; ${ }^{7}$ Eng $^{0}$-Agr ${ }^{\circ}$, Dr., Coordenador de Pesquisa e Desenvolvimento - Herbicidas. Arysta LifeScience. Rua Jundiaí, 50 - 9aandar - Paraíso, 04001-904, São Paulo, SP, <roberto.toledo@arystalifescience.com>. 
under rain simulation equivalent to 2.5 up to $65 \mathrm{~mm}$ rain, one day after application (DAA). On the third assay, the effect of the time intervals between herbicide application and the first rain on herbicide leaching $\left(0,1,7,15\right.$ and 30 days) on the straw $\left(10 t h^{-1}\right)$ was evaluated under the same rainfall amounts simulated in the second study. For the second and third assays an additional simulation of $20 \mathrm{~mm}$ at 07 and 14 days after the opening rains (DAOR) was carried out. The results obtained in second and third assays was adjusted by the Mitscherlich model $\left(Y=a^{*}\left(1-10^{\wedge}\left(-c^{*}(x+b)\right)\right)\right)$. The herbicide was quantified by HPLC. The results from the first assay demonstrated that straw amounts equal or superior to $5 t h a^{1}$ present an interception almost equivalent to the total of the applied herbicide with transposition being null. In the second assay, it can be observed that the higher the amount of straw, the smaller the total amount leached, mainly for 15 and $20 t h^{1}$. In the third assay, the results indicated that the longer the time interval between herbicide application and first rain, the smaller the total leaching of the product by maximum precipitation (65 $\mathrm{mm}$ ). With regard to rainfall at 7 and 14 DAOR in the second and third assays, small amounts extracted were observed, considering that a great part of amicarbazone was leached with the first rains, indicating that the first $20 \mathrm{~mm}$ of simulated rain were important for most amicarbazone leaching retained by the straw during application.

Keywords: Amicarbazone, herbicides, straw, leaching.

\section{INTRODUÇÃO}

Em áreas de colheita de cana crua são deixadas sobre o solo de 5 a 20 toneladas de palha por hectare. A quantidade de palha deixada no solo é dependente de características da variedade e do ambiente, como facilidade de despalha do colmo, hábito de crescimento da touceira, uniformidade em altura e tamanho dos ponteiros, produtividade e desenvolvimento da cana (Manechini, 1997). A palha afeta o estabelecimento e o crescimento de plantas daninhas em áreas cultivadas, reduzindo a amplitude térmica do solo, interceptando alguns comprimentos de luz necessários à germinação de algumas espécies de plantas daninhas, formando uma barreira física à emergência de plantas daninhas e aumentando a população de microrganismos que podem decompor as sementes destas plantas, além dos possiveis efeitos alelopáticos, que inibem a germinação e/ou o crescimento inicial das plantas daninhas. Apesar disso, algumas plantas daninhas estão sendo selecionadas em áreas de colheita de cana crua, como Ipomoeagrandifolia, Ipomoea quamoclit, Ipomoea nil, Merremia cyssoides, Euphorbia heterophylla, Bidens pilosa (Velini \& Martins, 1998; Martins et al., 1999; Velini \& Negrisoli, 2000; Correa \& Durigan, 2004).

Quando um herbicida é aplicado sobre a palha, é interceptado pela superficie desta e torna-se vulnerável à volatilização e/ou fotólise, até ser lixiviado para o solo (Locke \& Bryson, 1997). Lamoreaux et al. (1993) ressaltam que o transporte de herbicidas da palha para o solo é dependente da capacidade da palha de cobrir o solo e reter estes herbicidas, das características físico-químicas do herbicida, bem como do período em que a área permanece sem chuva após a aplicação. A partir do momento que esses herbicidas atingem o solo, apresentam maior distribuição e persistência, devido aos canais formados pelos restos vegetais ou por organismos do solo e, principalmente, pela amenização dos processos de degradação (Jones Jr. et al., 1990; Sorenson et al., 1991).

Amicarbazone é um herbicida pertencente ao grupo químico das triazolinonas, que apresenta formulação em grânulos dispersíveis em água (WG), facilitando o seu manuseio e conferindo maior segurança ao aplicador. Essa molécula contém um novo ingrediente ativo (700 g amicarbazone $\mathrm{kg}^{-1}$ ), apresentando elevada solubilidade em água (4,6 $\mathrm{g} \mathrm{L}^{-1}$ a $\left.\mathrm{pH} 4-9\right)$ e baixa pressão de vapor $\left(1,3 \times 10^{-6} \mathrm{~Pa}\right.$ a $\left.20^{\circ} \mathrm{C}\right)$ (Toledo et al., 2004). Esse herbicida é recomendado nas aplicações em pré e pós-emergência inicial para controle de amplo espectro de plantas daninhas que competem com as plantas de cana-de-açúcar. Quando aplicado em pré-emergência, é absorvido pelas raízes e se transloca via xilema, pelo fluxo de transpiração. No entanto, quando aplicado em pósemergência, predomina a absorção foliar, sendo sua ação de contato (Toledo et al., 2004). 
No entanto, estudos mais detalhados para entender o comportamento do herbicida em áreas de cana crua são necessários. A presente pesquisa teve como objetivo avaliar a dinâmica do herbicida amicarbazone (Dinamic) aplicado sobre diferentes quantidades de palha de canade-açúcar.

\section{MATERIAL E MÉTODOS}

A pesquisa foi conduzida no Núcleo de Pesquisas Avançadas em Matologia (NuPAM) FCA/Unesp - Botucatu, SP, onde foram realizadas as aplicações do amicarbazone (Dinamic) e as simulações de chuva nas palhas de canade-açúcar. As análises do amicarbazone, para determinação quantitativa, foram realizadas no Departamento de Agricultura - Laboratório de Matologia - FCA/Unesp - Botucatu, SP, utilizando-se um cromatógrafo líquido de alta eficiência equipado com detector espectrofotométrico UV-visivel e coluna cromatográfica Octadecyl $\mathrm{C}_{18}$.

As aplicações do herbicida amicarbazone e as simulações de chuva foram realizadas com um pulverizador instalado no NuPAM FCA/Unesp - Botucatu, SP. O herbicida foi aplicado com uma barra de pulverização constituída por quatro pontas de pulverização do tipo leque XR 110.02, espaçadas de $50 \mathrm{~cm}$, e mantida a $50 \mathrm{~cm}$ de altura do alvo, operando numa velocidade de $1,0 \mathrm{~m} \mathrm{~s}^{-1}$ e volume de calda de $200 \mathrm{~L} \mathrm{ha}^{-1} \mathrm{Em}$ todos os ensaios foram aplicados 2,0 kg de Dinamic ha-1, sendo o equivalente a $1.400 \mathrm{~g}$ de amicarbazone ha ${ }^{-1}$. Para simulação de chuva, a barra de pulverização foi constituída por três pontas de pulverização TK -SS-20 de alta vazão, espaçadas de $50 \mathrm{~cm}$, mantida a $1,4 \mathrm{~m}$ de altura do alvo e operada para produção de uma lâmina correspondente a $2,5 \mathrm{~mm}$ de precipitação, a cada passada do pulverizador, gerando uma intensidade média de precipitação de $115 \mathrm{~mm} \mathrm{~h}^{-1}$.

\section{Interceptação do amicarbazone pela palha da cana-de-açúcar}

Para estudo da interceptação do Dinamic (amicarbazone) pela palha da cana-de-açúcar foram realizados dois testes. No primeiro, utilizaram-se unidades experimentais de $0,016014 \mathrm{~m}^{2}$, nas quais foram colocadas as quantidades de palha de cana-de-açúcar equivalentes a: $0,1,2,5,5,7,5,10,15$ e $20 \mathrm{t}$ de palha ha-1. No segundo estudo, as unidades experimentais continham $0,04909 \mathrm{~m}^{2}, \operatorname{com} 5$, 10,15 e 20 t de palha de cana-de-açúcar ha-1. Para os dois testes, os tratamentos tiveram quatro repetições.

No primeiro teste, logo após a aplicação, os alvos plásticos previamente posicionados sob a camada de palha foram lavados com volume de $50 \mathrm{ml}$ de água destilada. No segundo, logo após a aplicação, os funis posicionados abaixo das unidades experimentais foram lavados com volume de $1,0 \mathrm{~L}$ de água destilada. As amostras obtidas foram armazenadas para análise no laboratório; posteriormente, o amicarbazone que transpôs a palha no momento da aplicação foi quantificado.

\section{Lixiviação do amicarbazone aplicado na palha de cana-de-açúcar}

No segundo ensaio foram utilizadas unidades experimentais de $0,04909 \mathrm{~m}^{2}$, com palha equivalente a 5, 10, 15 e 20 t de palha de canade-açúcar ha ${ }^{-1}$. Um dia após a aplicação foram realizadas simulações de chuva com volumes equivalentes a $2,5,5,10,20,35,50$ e $65 \mathrm{~mm}$ e intensidade média de $115 \mathrm{~mm} \mathrm{~h}^{-1}$. A água que transpôs a palha foi coletada em um recipiente, medindo-se o volume e retirando deste uma alíquota para quantificação do herbicida lixiviado por meio de análise cromatográfica. Aos 7 e 14 dias após aplicação das primeiras lâminas de chuva $(2,5$ a $65 \mathrm{~mm})$, aplicou-se mais uma lâmina de $20 \mathrm{~mm}$ para avaliar a possibilidade de liberação do produto que poderia ainda estar retido na palha. Foram utilizadas quatro repetições para cada quantidade de palha.

Os dados obtidos neste ensaio foram usados na análise de regressão, utilizando modelo de Mitscherlich $Y=a^{*}\left(1-10^{-c^{*}(b+x)}\right)$, em que:

$Y$ : é a quantidade do herbicida lixiviado em g ha ${ }^{-1}$; e $a, b$ e c: são parâmetros da equação, sendo $a$ a quantidade máxima do herbicida retirada pela lâmina de chuva aplicada; $b$, o deslocamento lateral da curva; $c$, a concavidade da curva; e $x$, a quantidade de chuva simulada ( $\mathrm{mm})$.

O procedimento permite avaliar a quantidade de produto que passa pela palha e pode 
efetivamente atingir o solo na ocorrência de diferentes quantidades de chuva.

\section{Efeito dos intervalos entre a aplicação e a primeira chuva na lixiviação do herbicida}

Para o terceiro ensaio, foi utilizada a unidade experimental de $0,04909 \mathrm{~m}^{2}$, porém somente com a quantidade de $10 \mathrm{t}$ de cana-deaçúcar ha $\mathrm{a}^{-1}$. O intervalo entre a aplicação e as simulações de chuva foram de $0,1,7,15$ e 30 dias. Após aplicação, os suportes contendo as palhas foram levados para casa de vegetação e mantidos até o intervalo de tempo estipulado, quando foram realizadas as simulações de chuva com as lâminas equivalentes a 2,5, 5 , $10,20,35$, 50 e $65 \mathrm{~mm}$, seguindo-se o procedimento descrito no ensaio anterior para obtenção das amostras. Aos 7 e 14 dias após aplicação das primeiras lâminas de chuva, para cada intervalo de tempo, foi aplicada mais uma lâmina de $20 \mathrm{~mm}$, com o mesmo objetivo do ensaio anterior. Novamente, foram utilizadas quatro repetições por quantidade de palha.

Os dados obtidos neste ensaio foram usados na análise de regressão, utilizando o modelo de Mitscherlich $\mathrm{Y}=\mathrm{a} *\left(1-10^{-\mathrm{c}^{*}(\mathrm{~b}+\mathrm{x})}\right)$.

\section{Procedimento de análise das amostras}

Para quantificação do amicarbazone, foram retirados $5 \mathrm{~mL}$ de cada amostra. Essas alíquotas foram elevadas a um volume de $10 \mathrm{~mL}$ de metanol: água em 50: $50\left(\mathrm{v} \mathrm{v}^{-1}\right)$. Posteriormente, as soluções assim obtidas foram filtradas e devidamente analisadas por cromatografia líquida de alta eficiência. Os sinais analíticos dos picos de amicarbazone das amostras transformados em área foram comparados com a curva de calibração das soluções-padrão do herbicida amicarbazone.

\section{RESULTADOS E DISCUSSÃO}

\section{Interceptação do amicarbazone pela palha de cana-de-açúcar}

Na Figura 1 são apresentados os dados de interceptação do herbicida amicarbazone para as quantidades de palha de $0,1,2,5,5,7,5,10$, 15 e 20 t de palha de cana-de-açúcar ha-1, no momento da aplicação, sendo retidos $0,33,73$, $85,93,98,99$ e $100 \%$ do herbicida aplicado, respectivamente. Em relação às unidades experimentais de $0,04909 \mathrm{~m}^{2}$, a porcentagem de interceptação obtida para $0,5,10,15$ e $20 \mathrm{t}$ palha de cana ha ${ }^{-1}$ foi de $96,99,100$ e $100 \%$, respectivamente.

Portanto, observa-se que em quantidade de palha igual ou superior a $5 \mathrm{t} \mathrm{ha}^{-1}$ há interceptação quase que total do herbicida aplicado, sendo praticamente nula a quantidade de produto que atinge o solo no momento da aplicação. Isso demonstra a necessidade de chuva após a aplicação, pois o produto precisa atingir o solo para atuar de forma eficaz.

\section{Lixiviação do amicarbazone aplicado na palha de cana-de-açúcar}

Os resultados ajustados pelo modelo de Mitscherlich (Tabela 1 e Figura 2) demonstraram que a quantidade de amicarbazone lixiviada pelas lâminas aplicadas variou conforme a quantidade de palha utilizada $(5,10,15 \mathrm{e}$ $\left.20 \mathrm{t} \mathrm{ha}^{-1}\right)$. Para $5 \mathrm{t}$ de palha de cana-de-açúcar ha-1, a lâmina de 2,5 mm lixiviou $40 \%$ do produto aplicado, enquanto para 10, 15 e 20 t de palha ha ${ }^{-1}$ a mesma lâmina lixiviou 33, 25 e $25 \%$ do produto aplicado, respectivamente. Em estudo realizado em casa de vegetação, Negrisoli et al. (2006) obtiveram controle excelente de Brachiaria plantaginea, Brachiaria decumbens e Ipomoea grandifolia com amicarbazone aplicado sobre $5 \mathrm{t} \mathrm{ha}^{-1}$, após simulação de chuva de $2,5 \mathrm{~mm}$. O efeito das primeiras chuvas simuladas no processo de lixiviação para cada quantidade de palha de cana-deaçúcar foi mais intenso em relação às lâminas aplicadas posteriormente. Isso ocorreu devido à maior quantidade de herbicida disponível para lixiviação logo após a aplicação desse produto. A lâmina de $20 \mathrm{~mm}$ demonstrou ser importante para definir a saída de grande parte do herbicida aplicado, lixiviando $76 \%$ (1.068 $\left.\mathrm{g} \mathrm{ha}^{-1}\right), 75 \%$ (1.044 $\left.\mathrm{g} \mathrm{ha}^{-1}\right), 63 \%$ (883 $\left.\mathrm{g} \mathrm{ha}^{-1}\right)$ e $58 \%\left(814 \mathrm{~g} \mathrm{ha}^{-1}\right)$ da quantidade total aplicada para 5, 10, 15 e 20 t de palha de cana-de-açúcar ha-1 ${ }^{-1}$, respectivamente (Figura 3). A quantidade de amicarbazone lixiviada pelas lâminas até $65 \mathrm{~mm}$ para as quantidades de 5 , 10,15 e $20 \mathrm{t}$ de palha de cana-de-açúcar hafoi, respectivamente, de $81 \%$ (1.139 $\left.\mathrm{g} \mathrm{ha}^{-1}\right)$; $81 \%\left(1.135 \mathrm{~g} \mathrm{ha}^{-1}\right), 67 \%\left(937 \mathrm{~g} \mathrm{ha}^{-1}\right)$ e $61 \%$ $\left(853 \mathrm{~g} \mathrm{ha}^{-1}\right)$ do total aplicado. Em trabalho 


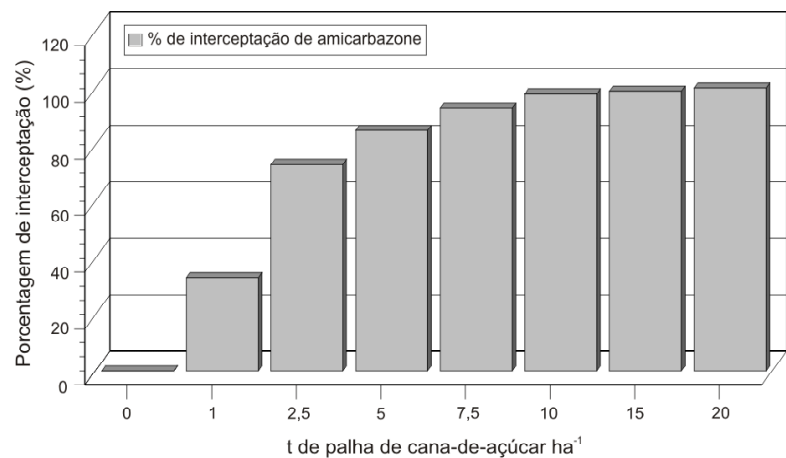

Figura 1 - Interceptação do amicarbazone, no momento da aplicação, sobre as diferentes quantidades de palha de canade-açúcar estudadas (dados ajustados pelo modelo de Mitscherlich).

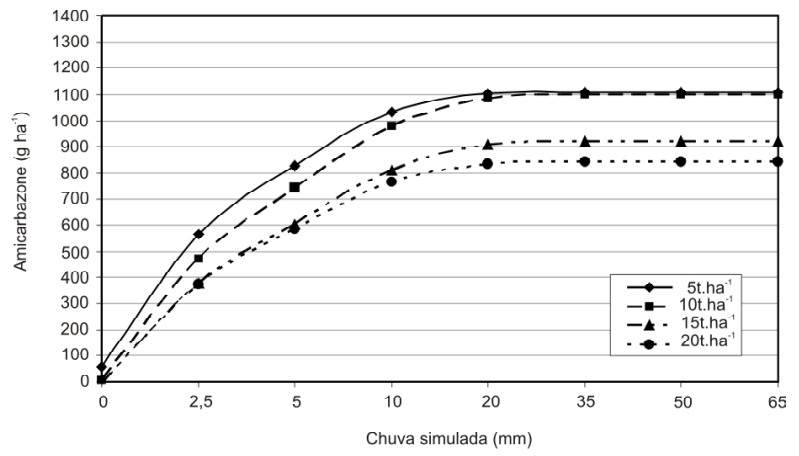

Figura 2 - Lixiviação do amicarbazone em função de diferentes volumes de chuva simulada e em diferentes quantidades de palha de cana-de-açúcar sobre o solo (dados ajustados pelo modelo de Mitscherlich).

Tabela 1 - Parâmetros obtidos para lixiviação de amicarbazone (Dinamic) na regressão ajustada pelo modelo de Mitscherlich em diferentes quantidades de palha de cana-de-açúcar

\begin{tabular}{|c|c|c|c|c|c|}
\hline \multirow{2}{*}{$\begin{array}{c}\text { Palha de cana-de-açúcar } \\
\left(\mathrm{t} \mathrm{ha}^{-1}\right)\end{array}$} & \multicolumn{5}{|c|}{ Parâmetros do modelo de Mitscherlich } \\
\cline { 2 - 6 } & $\mathrm{a}$ & $\mathrm{b}$ & $\mathrm{c}$ & $\mathrm{r}^{2}$ & $\mathrm{~F}$ \\
\hline 5 & $1.107,76$ & 0,2010 & 0,1147 & 0,9959 & $2838,36^{* *}$ \\
10 & $1.098,58$ & 0,0385 & 0,0965 & 0,9948 & $1895,76^{* *}$ \\
\hline 15 & 921,11 & $-0,0434$ & 0,0934 & 0,9958 & $2226,28^{* *}$ \\
\hline 20 & 841,87 & $-0,0371$ & 0,1038 & 0,9956 & $2207,82^{* *}$ \\
\hline
\end{tabular}

semelhante, Cavenaghi et al. (2002) observaram que $65 \%$ do total aplicado de tebuthiuron, $65 \%$ de diuron, $72 \%$ de ametrine e $67 \%$ de sulfentrazone foram lixiviados de $10 \mathrm{t}$ de palha de cana-de-açúcar ha-1 com a lâmina de $65 \mathrm{~mm}$ de chuva um dia após a aplicação.

As simulações de chuva de $20 \mathrm{~mm}$ aplicadas aos 7 e 14 dias após as primeiras lâminas não lixiviaram quantidades significativas do herbicida, considerando-se que grande parte do amicarbazone havia sido lixiviada.

\section{Efeito dos intervalos entre a aplicação e a primeira chuva na lixiviação de amicarbazone (Dinamic)}

De acordo com os resultados ajustados pelo modelo de Mitscherlich (Tabela 2 e Figura 4), pode-se observar que a quantidade de amicarbazone (Dinamic) lixiviada pelas lâminas de chuva diminuiu com o aumento do intervalo de tempo entre a aplicação e a primeira chuva. Independente do intervalo de tempo, a lixiviação para as lâminas aplicadas de 2,5, 5, 10, 20, 35,50 e $65 \mathrm{~mm}$ seguiram um mesmo padrão, sendo observada diferenças maiores entre as quantidades lixiviadas nas primeiras lâminas $(2,5,5,10$ e $20 \mathrm{~mm})$ e diferenças menores entre as lâminas finais $(35,50$ e $65 \mathrm{~mm})$. Esses resultados são similares aos do ensaio anterior, em que a lâmina de $20 \mathrm{~mm}$ foi importante para lixiviação da maior parte do produto retido na palha, independentemente do intervalo de tempo entre a aplicação e a primeira chuva.

Os resultados das simulações de chuvas de $20 \mathrm{~mm}$ aos 7 e 14 dias após as primeiras lâminas $(2,5$ a $65 \mathrm{~mm})$ apresentaram valores distintos para cada intervalo de tempo, variando de 0,29 a $7,14 \%$ de lixiviação do total aplicado, não mostrando nenhuma correlação com a quantidade de produto já lixiviada ou o intervalo de tempo.

Conclui-se que quantidades de palhas de cana-de-açúcar próximas a $5 \mathrm{t} \mathrm{ha}^{-1}$ já são capazes de interceptar praticamente toda a calda de pulverização do herbicida testado. A primeira 


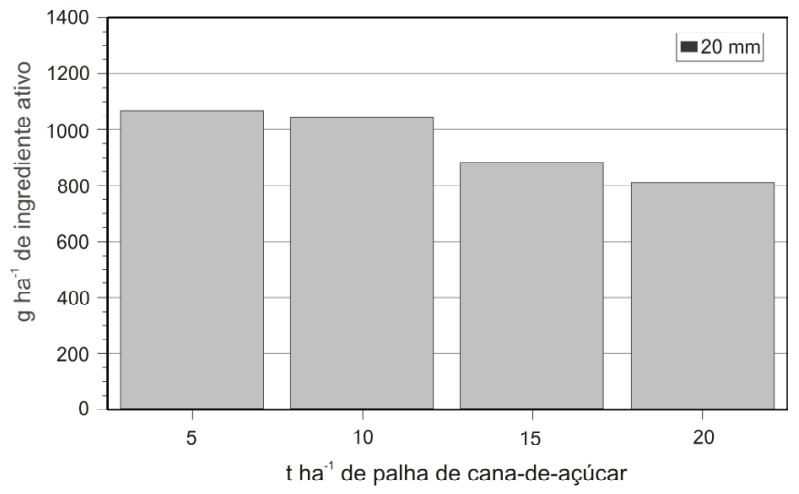

Figura 3 -Quantidade do amicarbazone lixiviada até a lâmina de $20 \mathrm{~mm}$, para as diferentes quantidades de palha de canade-açúcar.

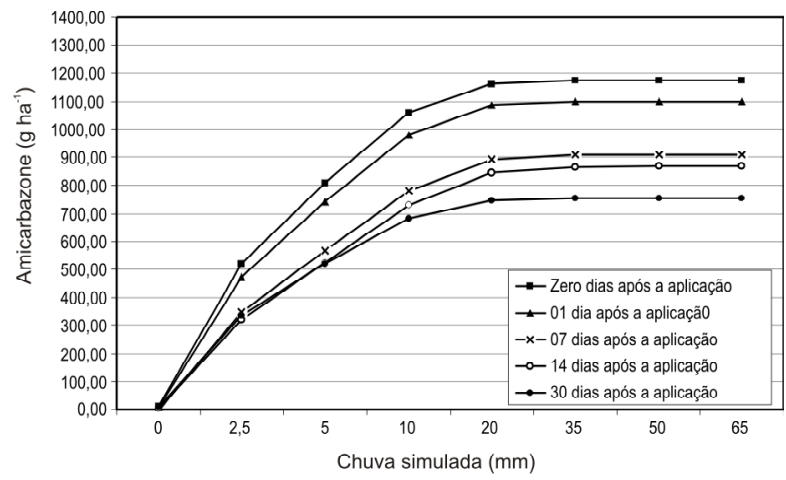

Figura 4 -Lixiviação do amicarbazone com diferentes intervalos de tempo entre a aplicação e a simulação de chuva (dados ajustados pelo modelo de Mitscherlich).

Tabela 2 - Parâmetros obtidos para lixiviação de amicarbazone (Dinamic) em diferentes intervalos de tempo entre a aplicação e a simulação de chuva pelo ajuste do modelo de Mitscherlich e em diferentes quantidades de palha de cana-de-açúcar

\begin{tabular}{|c|r|r|r|r|r|}
\hline \multirow{2}{*}{$\begin{array}{c}\text { Intervalo sem chuva após a aplicação } \\
\text { (dias) }\end{array}$} & \multicolumn{5}{|c|}{ Parâmetros do modelo de Mitscherlich } \\
\cline { 2 - 6 } & $\mathrm{a}$ & $\mathrm{b}$ & $\mathrm{c}$ & \multicolumn{1}{c|}{$\mathrm{r}^{2}$} & $\mathrm{~F}$ \\
\hline 0 & $1.174,60$ & 0,0417 & 0,1002 & 0,9973 & $3646,48^{* *}$ \\
\hline 1 & $1.098,59$ & 0,0385 & 0,0965 & 0,9949 & $1895,77^{* *}$ \\
\hline 7 & 910,10 & $-0,0213$ & 0,0849 & 0,9919 & $1103,37^{* *}$ \\
\hline 14 & 866,82 & 0,0347 & 0,0799 & 0,9905 & $932,35^{* *}$ \\
\hline 30 & 753,94 & 0,0425 & 0,1007 & 0,9956 & $2241,44^{* *}$ \\
\hline
\end{tabular}

chuva e os $20 \mathrm{~mm}$ de chuva iniciais são fundamentais para lixiviação do amicarbazone (Dinamic) da palha para o solo; a lixiviação é reduzida com o aumento do intervalo entre a aplicação e a primeira chuva.

\section{LITERATURA CITADA}

CAVENAGHI, A. L. et al. Dinâmica de herbicidas em palhada de cana-de-açúcar. In: CONGRESSO NACIONAL DA SOCIEDADE DOS TÉCNICOS AÇUCAREIROS E ALCOOLEIROS DO BRASIL, 8., 2002, Recife-PE. Anais... Piracicaba: STAB, 2002. p.170-174.

CORREA, N. M.; DURIGAN, J. C. Emergência de plantas daninhas em solo coberto com palha de cana-de-açúcar.

Planta Daninha, v. 22, n. 1, p. 11-17, 2004.

JONES JR, R. E.; BANKS, P. A.; RADCLIFFE, D. E. Alachlor and metribuzin movement and dissipation in a soil profile as influenced by soil surface condition. Weed Sci., v. 38, p. 589-597, 1990.
LAMOREAUX, R. J.; JAIN, R.; HESS, F. D. Efficacy of dimethenamid, metolachlor and encapsulated alachlor in soil covered with crop residue. Bringhton Crop Protec.

Conference - Weeds, v. 3, p. 1015-1020, 1993.

LOCKE, M. A.; BRYSON, C. T. Herbicide-soil interaction in reduced tillage and plant residue management systems. Weed Sci., v. 45, p. 307-320, 1997.

MANECHINI, C. Manejo da cana crua. In: SEMINÁRIO COPERSUCAR DE TECNOLOGIA AGRONÔMICA, 7., 1997, Piracicaba. Anais... Piracicaba: 1997. p. 309-327.

MARTINS, D. et al. Emergência em campo de dicotiledôneas infestantes em solo coberto com palha de cana-de-açúcar.

Planta Daninha, v. 17, n. 1, p. 151-161, 1999.

NEGRISOLI, E. et al. Controle de planta daninha pelo amicarbazone aplicado na presença de palha da cana-deaçúcar. In: CONGRESSO BRASILEIRO DA CIÊNCIA DAS PLANTAS DANINHAS, 25., 2006, Brasília-DF.

Resumos... Brasília: Sociedade Brasileira da Ciência das Plantas Daninhas, 2006. CD-ROM. 
SORENSON, B. A.; SHEA, P. J.; ROETH, F. W. Effects of tillage, application time and rate on metribuzin dissipation. Weed Res., v. 31, p. 333-345, 1991.

TOLEDO, R. E. B. et al. Dinamic (amicarbazone) - novo herbicida seletivo para o controle de plantas daninhas em pré e pós-emergência na cultura da cana-de-açúcar. In: CONGRESSO BRASILEIRO DA CIÊNCIA DAS

PLANTAS DANINHAS, 24., 2004, São Pedro. Anais... São Pedro: Sociedade Brasileira da Ciência das Plantas Daninhas, 2004. p. 451.
VELINI, E. D.; MARTINS, D. Efeito da palha de cana-deaçúcar sobre a germinação das principais espécies desta cultura. Botucatu: Universidade do Estado de São Paulo, 1998. 26 p. (Relatório Técnico)

VELINI, E. D.; NEGRISOLI, E. Controle de plantas daninhas em cana crua. In: CONGRESSO BRASILEIRO DA CIÊNCIA DAS PLANTAS DANINHAS, 22., 2000, Foz de Iguaçu. Palestras... Foz de Iguaçu: Sociedade Brasileira da Ciência das Plantas Daninhas, 2000. p. 148-164. 